\title{
FAULT DIAGNOSIS OF INDUCTION MOTOR DRIVE USING MOTOR CURRENT SIGNATURE ANALYSIS
}

\author{
Mrs.Ramya.D ${ }^{1}$, Dr.Rani Fathima Kamal Basha ${ }^{2}$, and Dr.Bharathi M.L ${ }^{3}$ \\ (ramya.devasahayam@gmail.com ${ }^{1}$, dr.ranifathima@gmail.com, ${ }^{2}$ bharathim115@gmail.com³ ${ }^{3}$ )
Assistant Professor, Sathyabama Institute of Science and technology,Chennai,India ${ }^{1}$, Lecturer,Al Musanna college of Technology Al Mulladah sultanate of oman ${ }^{2}$, \\ Assistant Professor, Sathyabama Institute of Science and technology,Chennai,India ${ }^{3}$
}

\begin{abstract}
Asynchronous motors are widely used in transportation, mining and in all electric drive application. It is robust. Compare to other motors it is easy to control and less cost. In this paper conditioning of motor is achieved. It has become necessary to monitor the condition of motor in industries. MCSA is the best method for conditioning of motor, we need single phase current of three phase induction motor to analyze the condition of monitor. So many faults will occur in the induction motor. Weare taking open switch fault in this induction motordrive.
\end{abstract}

Keywords:Inductionmotor,Currentsignatureanalysis(CSA), Voltagesignatureana lysis(VS A),motorsignature analysis(MCSA)

\section{Introduction}

Induction motor are two types, squirrel cage induction motor,slipring induction motor [1]. MCSA technique is used to monitor the condition of motor, initially this concept is proposed in 1970's [2]. This test is performed without interruption production in running condition under normal and load condition [3].

\section{COMPARISION OF FAULT TECHNIQUES}

TABLE-I: Comparision of fault techniques

\begin{tabular}{|l|l|l|l|}
\hline SL NO- & TITLE & AUTHORS & $\begin{array}{l}\text { METHODSOF } \\
\text { FAULTS }\end{array}$ \\
\hline 1. & MCSA & $\begin{array}{l}\text { William T.(Bill) } \\
\text { Thomson, Ronald } \\
\text { J.(Ron) Gilmore }\end{array}$ & $\begin{array}{l}\text { Stator faults, rotor } \\
\text { faults, bearing faults } \\
\text { vibration faults }\end{array}$ \\
\hline 2. & Park's transformation technique & $\begin{array}{l}\text { Dubravko, } \\
\text { Milikovic, Zagreb }\end{array}$ & $\begin{array}{l}\text { Rotor faults and } \\
\text { stator faults }\end{array}$ \\
\hline 3. & Axial leakage flux & $\begin{array}{l}\text { Carlos Perez Tello, } \\
\text { Julio Gomez Sarduy }\end{array}$ & $\begin{array}{l}\text { Bearing faults, Stator } \\
\text { faults, Rotor faults, } \\
\text { Ecentricity }\end{array}$ \\
\hline
\end{tabular}




\section{WHY MCSA???}

Motor will run continuously even when fault occurs. We can analyse the fault parameters by using single phase in the three phase induction motor [4].

\section{SYSTEMATIC DIAGRAM:}

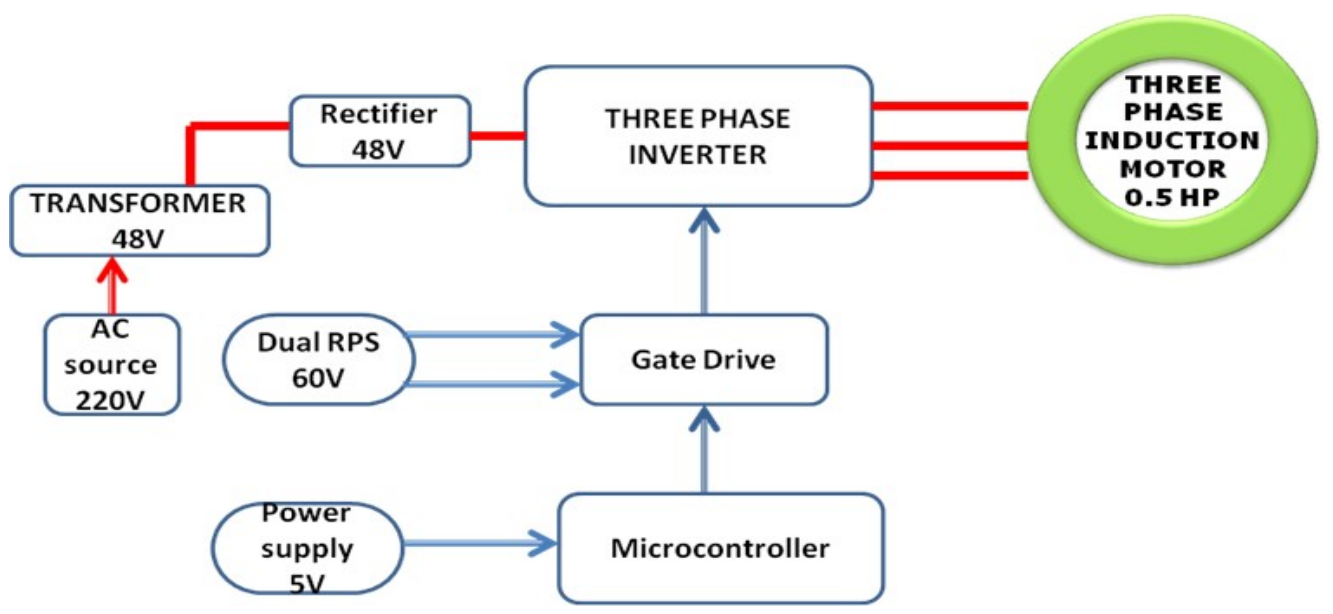

Fig.1.Systematic diagram of the system

The above block diagram in fig. 1 shows the existing system. It consists of A.C source, transformer, rectifier, 3 phase inverter, dual RPS, gate driver, power supply and microcontroller [5]. The ac source is given to transformer to step down the voltage and given to rectifier to convert from ac to dc. The dc is given to three phase inverter [6]. Above is controlled by gate driver circuit and microcontroller. Gate driver has dual regulated power supply and microcontroller has separate power supply. The motor is controlled by the inverter.

In existing system, if fault occurs the machine will be damaged and it will take time to bring into normal condition and damage cost will also increase and efficiency of machine will be decreased compared to before.

\section{PROPOSED SYSTEM:}




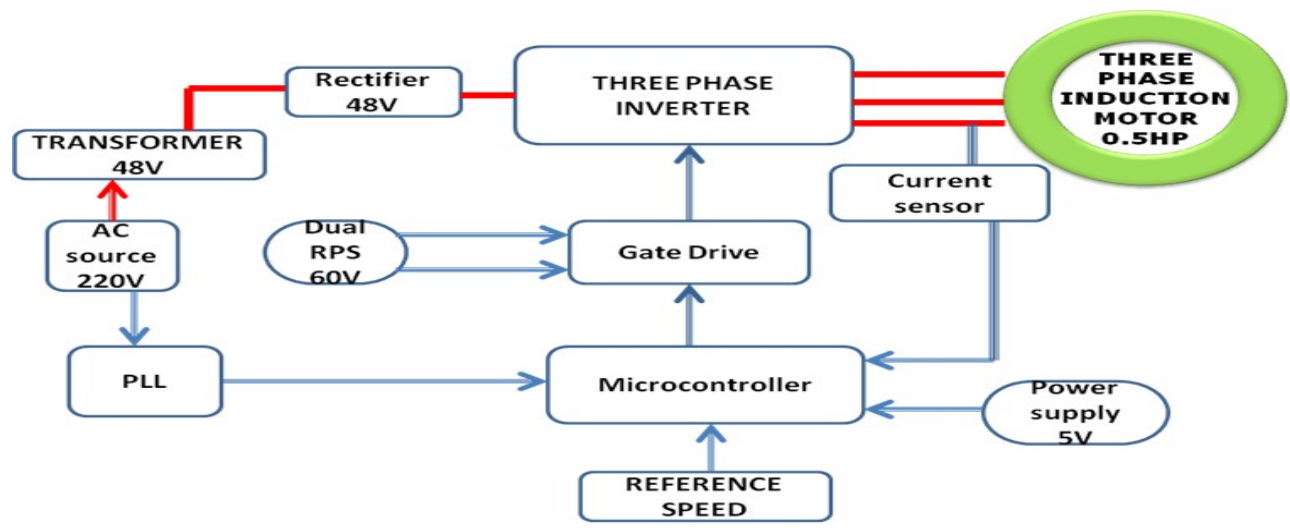

Fig.2.Block diagram of proposed system

The above block diagram shows the proposed system in fig.2. It consists of PLL, A.C source, transformer, rectifier, 3 phase inverter, dual rps, gate driver, power supply and microcontroller. The ac source is given to transformer to step down the voltage and is given to rectifier to convert from ac to dc. The dc is given to three phase inverter. It is controlled by Gate driver and microcontroller. The dual Regulated power supply and power supply are connected to gate driver circuit and microcontroller. In this system we will take speed as a reference and given to microcontroller. We will take output current using current sensor and it is controlled by operational amp.

In proposed system here we are using mosfets as switches in inverter. Fault will be predicted if any current/voltage value of phase is changed from set value. If the set value crosses across the switch it will be damaged and current will flow in another switch it is called as phase change over switch and motor will run continuously and switch will run continuously and switch will be in maintenance. During fault condition, the current flowing through switch will be taken through current sensor by using spectrum analyzer

\section{SIMULATION:}

\section{SUBSYSTEM1:}

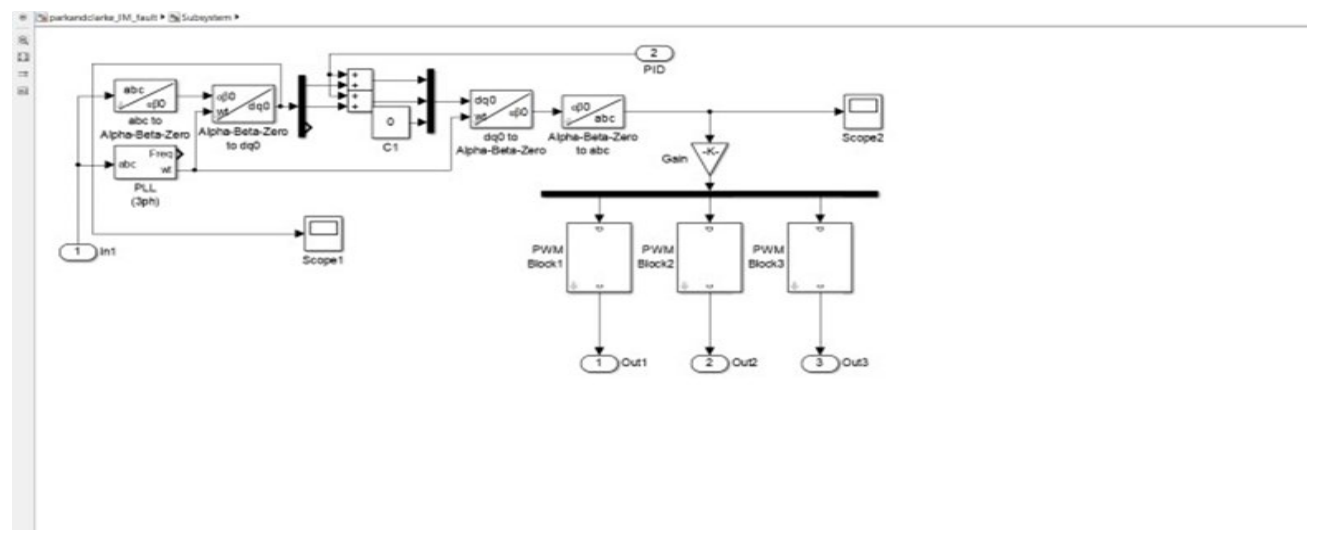

Fig.3.Subsystem 1 


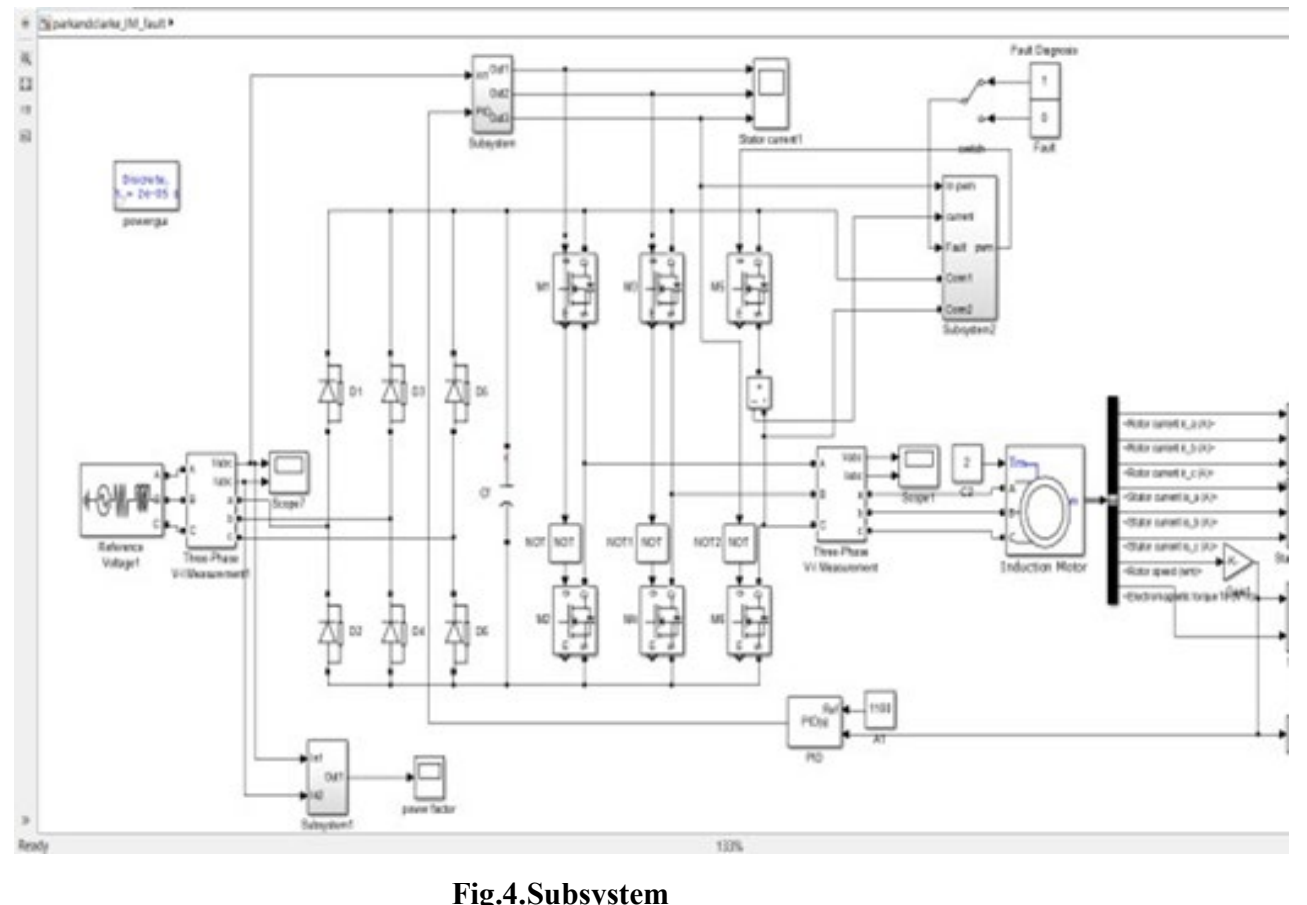

Fig.4.Subsystem

SUBSYSTEM2: 


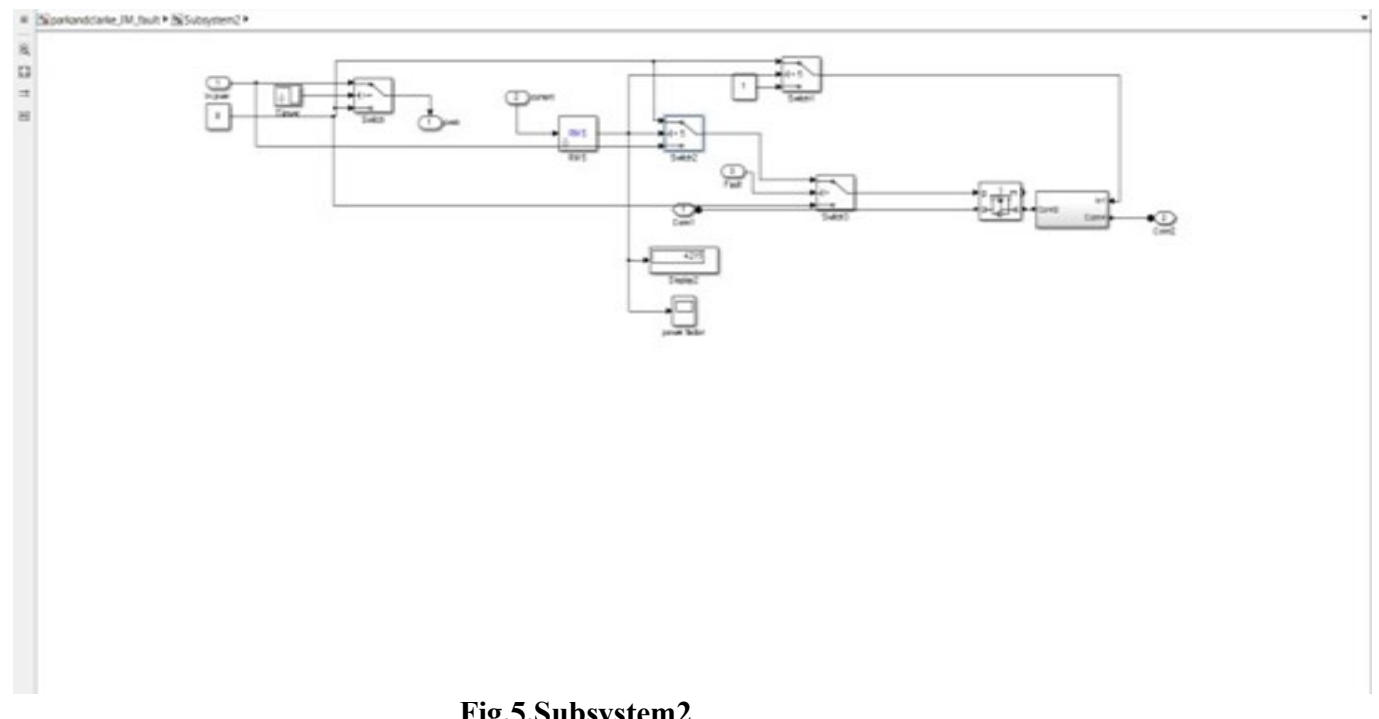

Fig.5.Subsystem2

CIRCUIT DIAGRAM: 


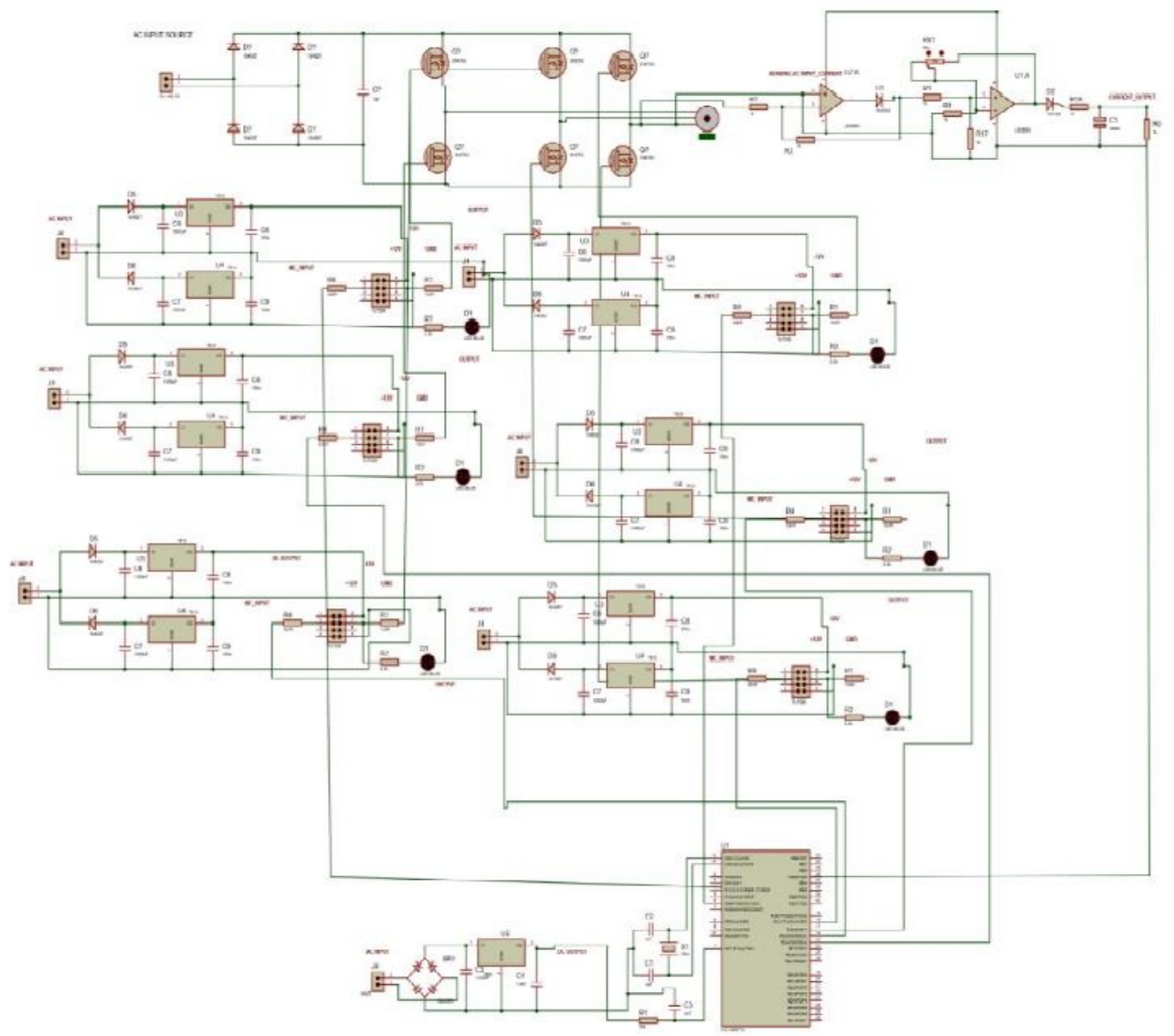

Fig.6 .Circuit diagram

SIMULATION OF OUTPUT FAST FOURIER TRANSFORMATION AND PARK AND CLARKE TRANSFORMATION ANALYSIS

\section{BEFORE FAULT :}

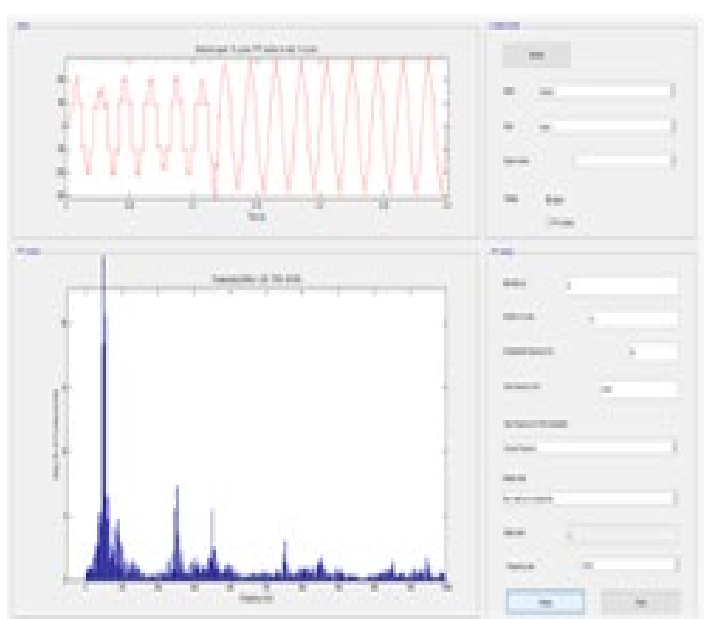

\section{AFTER FAULT :}

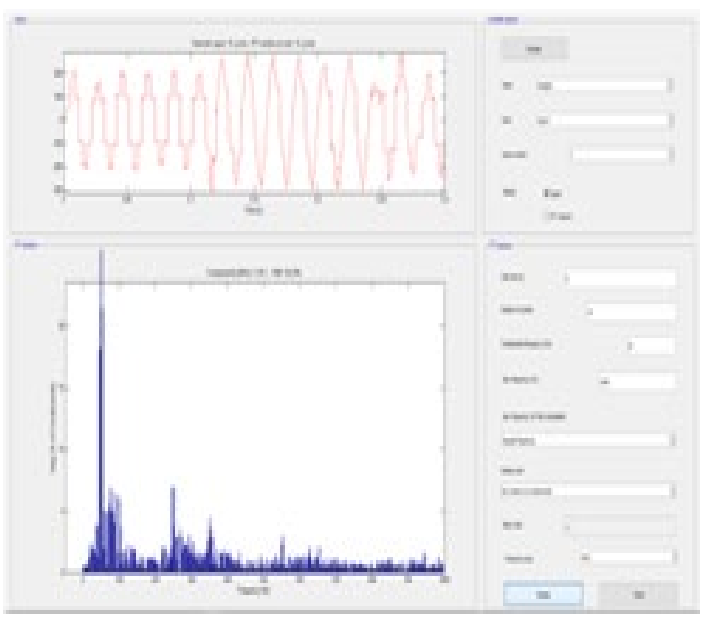

Fig.7.Before and after fault using fast fourier transformation 


\section{BEFORE FAULT :}

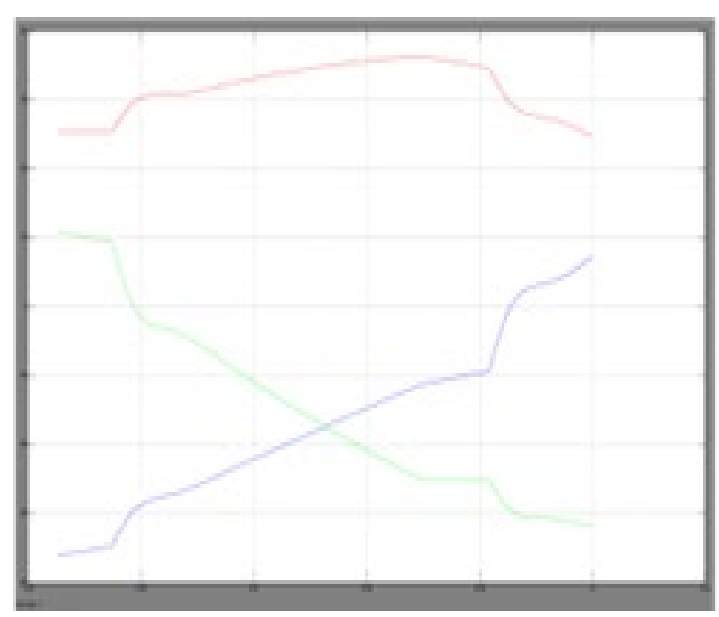

AFTER FAULT :

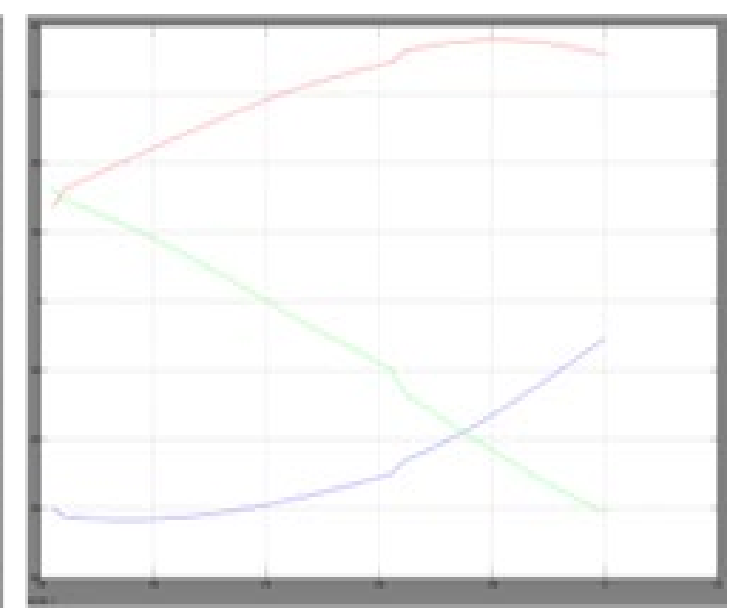

Fig.8.Before and after fault using Park and Clarke transformation

In the subsystem block of the Simulation Park and Clarke transformation shown in fig $3,4 \& 5$ is used for the open switch fault. In the park and Clarke transformation the three phase current lines in the $\mathrm{x}$-axis as the direct axis and $\mathrm{y}$-axis as the quadrature axis changes before the fault and after the fault.The fast fourier transform analysis shown in fig.7\&8is used to take the current spectrum graph. In the current spectrum graphfrom the figure:8the $\mathrm{x}-\mathrm{axis}$ is the frequency and the $y$-axis is the current magnitude indB

\section{EXPLANATION OF CIRCUIT DIAGRAM:}

The above hardware circuit diagram in fig. 6 is controlled by microprocessor, initially the supply given to inverter, here in this inverter mosfets are used as a switches to control the motor. These switches are connected to gate drive, here we are using 3-phase inverter, each leg has two switches, each switch has each gate drive. The upper leg of Inverter is worked in positive sequence and lower leg of Inverter is worked in negative sequence. Each upper leg switches has each gate drive but for lower leg two switches has one common gate driver circuit because here we are considering the fault in only phase. So remaining two switches are same ground. In fault phase we arranged acurrent sensor to measure the current flowing through the faulty phase, it is connected to op- amp. The phase change over switch is used in faulty section, it acts like a bypass to current flow, the phase change over switch will work when the current flowing through any phase changes i.e., if it exceeds the set value of current 


\section{OPEN SWITCH FAULT:}

The open switch switch fault created across one mosfet switch in the inverter circuit. There is no fault diagnosis frequency equation for these fault in the induction motor drive. The fault diagnosis frequency equation is only there for stator, rotor and eccentricity faults in the induction motor

\section{VOLTAGE ACROSS CURRENTSENSOR:}

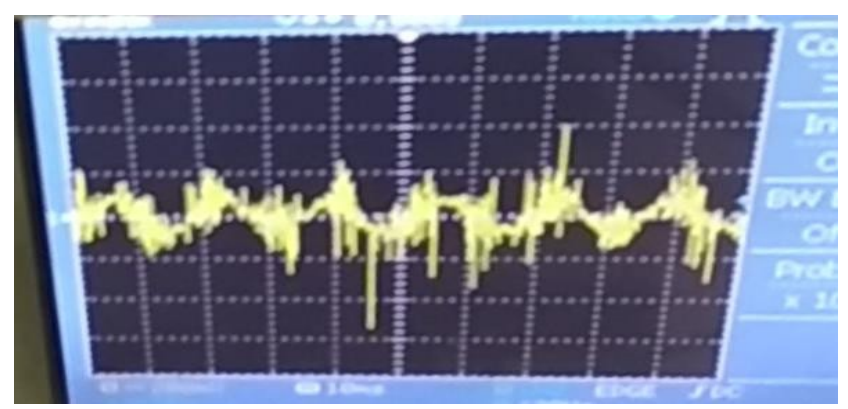

Fig. 9.Voltage across sensor

\section{COMPARISON OF SIMULATION AND HARDWARE RESULTS:}

The results from simulation are taken using FFT analysis, in simulation the results are before fault and after fault are taken but in hardware results are taken from C.R.O is in above fig.9. In hardware the graph taken across the current sensor, and graphs are before fault condition only. We can use spectrum analyzer to take graphs from hardware but due to economical reasons.

\section{CONCLUSION:}

These are the results from the simulation and hardware simulation results are taken using FFT spectrum analyzer. But in hardware results are taken using CRO due to economical reasons. In the simulation purpose only we get FFT graph but inreal time hardware we didn't have the data acquisition card (or) spectrum analyzer. In the future purposes we can connect the data acquisition card to this project. This project is used for industrial purpose to predict and diagnose the fault. We can rectify the fault and the motor will be in safe condition. The damage level of the induction motor will be low. If we didn't recognize the fault then the motor will get damage due to this huge money loss in the industry.

\section{ADVANTAGES OF MCSA:}

- Motor will run continuously even in fault condition.

- Online fault monitoring can be done without shutdown the motor. 


\section{APPLICATIONS OF MCSA:}

- This technique is mainly used in power stations to avoid damage.

- The MCSA is used for prevent the hazardousdamageintheinductionmotor

\section{References:}

[1] Sahoo, Saroja Kanti, and Nudurupati Krishna Kishore. "Battery state-of-charge-based control and frequency regulation in the MMG system using fuzzy logic." IET Generation, Transmission \& Distribution (2020).

[2] Emad, Alaa, Mohmed El-Shimy, Ghada Amer, and Ilham Ihoume. "Power Management Control of Hydrogen-Based System Using Fuzzy Logic Method." In 2020 International Conference on Electrical and Information Technologies (ICEIT), pp. 1-6. IEEE, 2020.

[3] Bharathi ML, Kirubakaran D. Neural Network Controlled High-Step Up Based SinglePhase PV Inverter System with Improved Dynamic Response. Journal of Computational and Theoretical Nanoscience. 2017 Jan 1;14(1):421-9.

[4] J. Dafni Rose, K. Vijayakumar and S. Sakthivel, "Students performance analysis system using cumulative predictor algorithm”, Int. J. Reasoning-based Intelligent Systems, Vol. 11, No. 2, 2019.

[5] Vijayakumar. K, Nawaz Sherif. T, Gokulnath.S, "Automated Risk Identification using Glove algorithm in Cloud Based Development Environments", International Journal of Pure and Applied Mathematics Volume 117 No. 162017.

[6] P Illavarason, Renjith J Arokia, P Mohan Kumar, 2019, "Comparative study and an improved algorithm for iris and eye corner detection in real time application" ComputerAided Developments: Electronics and Communication, CRC Press, PP-91-98. 